\title{
La comercialización de energía eléctrica a través de cooperativas de consumo
}

\author{
Dra. Vega María Arnáez Arce \\ Profesora de Derecho Administrativo \\ Universidad de Deusto
}

Recibido: 24.05.11

Aceptado: 05.07 .11

Sumario: I. Introducción. II. La externalización de la actuación de las Administraciones Públicas: 2.1. Significado y Alcance. 2.2. La prestación de servicios de interés general mediante personas jurídicas de base privada III. Régimen jurídico de la comercialización de la electricidad: 3.1. Evolución de la regulación del sector eléctrico: del servicio público al servicio de interés general. 3.2. La distinción de actividades en la LSE. La comercialización de la electricidad. IV. Las cooperativas eléctricas: 4.1. Breve aproximación al origen y la evolución de las cooperativas eléctricas en nuestro país. 4.2. Aproximación al marco jurídico básico de las cooperativas eléctricas. 4.3. Reconocimiento normativo y jurisprudencial de las cooperativas eléctricas como sociedades comercializadoras de electricidad. V. A modo de conclusión.

Resumen: En este trabajo se analiza el régimen jurídico básico de las cooperativas eléctricas en su naturaleza jurídica de cooperativas de consumo que tienen por objeto social la distribución de la energía eléctrica y la comercialización de todo tipo de productos energéticos relacionados con la electricidad. Dicho análisis parte de la importancia cuantitativa y cualitativa de las cooperativas eléctricas, que representan en la actualidad un modelo de gestión eficiente que les permite garantizar el abastecimiento de electricidad tanto a sus socios como a cada vez un mayor número de clientes a precios muy económicos y competitivos, mediante el desarrollo de acuerdo con los principios y procedimientos de actuación propios de lo que se puede denominar un modelo energético sostenible.

Palabras clave: Desregulación, simplificación y externalización; servicios de interés general; suministro, distribución y comercialización de electricidad; concurrencia competitiva; cooperativas de consumo eléctricas; ahorro y eficiencia energética.

\footnotetext{
Abstract: This paper analyses the basic legal system of electric cooperatives in their judicial aspect as consumer cooperatives whose social purpose is distribution of electric energy and the commercialisation of all types of electricity-related energy products. The study is based on the quantita-
} 
tive and qualitative role of electric cooperatives which are currently an example of an efficient management model, ensuring that electricity is provided to their members as well as to an increasing number of other customers at very economical competitive prices. This is achieved by development in accordance with the principles and procedures typical of what can be called a sustainable energy model.

Key words: Deregulation, simplification and outsourcing; services of general interest; supply, distribution and commercialisation of electricity; competition concurrency; electric consumer cooperatives; energy saving and efficiency. 


\section{Introducción}

A lo largo de su evolución, el Derecho administrativo se ha configurado como el sector del ordenamiento jurídico que tiene por objeto la atribución de diversas potestades y prerrogativas de las Administraciones Públicas, al amparo de su función o misión de servicio a la garantía y realización de los intereses generales.

De igual modo, y como contrapeso del haz de las Potestades atribuidas a las Administraciones Públicas, el ordenamiento administrativo ha ido reconociendo y atribuyendo una sucesión de garantías de los administrados que, con el paso de tiempo, han ido creciendo tanto cuantitativa como cualitativamente como resorte para hacer frente a los poderes exorbitantes que implica el ejercicio de las funciones públicas.

En definitiva, el Derecho administrativo se puede definir como un derecho de prerrogativas y garantías en el que el ejercicio de las Potestades administrativas está sometido a una sucesión de principios y exigencias con la finalidad de asegurar la actuación objetiva de los poderes públicos en el ejercicio de sus funciones y competencias siempre al servicio de la realización del interés general.

Sin embargo, y aún cuando cualquier manifestación de las actuaciones de los Poderes Públicos es el resultado de un previo procedimiento administrativo concebido como una garantía para los administrados, lo cierto es que su tramitación evidencia una ralentización en la gestión de los intereses generales y en la prestación de los servicios públicos que lleva a cuestionar su virtualidad como garantía de los intereses de los ciudadanos.

De este modo, lo que está previsto y concebido en nuestro ordenamiento jurídico como una garantía de los administrados se llega a convertir en una auténtica traba que dificulta la gestión de los servicios públicos en los términos y con la diligencia y eficacia deseable para dar respuesta a las demandas y necesidades de los mismos.

Como reacción a esta situación, se plantea el fenómeno de la huida del derecho administrativo, o lo que es lo mismo, de la creación de una ficción jurídica consistente en la externalización de la gestión de los intereses y los servicios públicos a través de personas jurídicas o de organizaciones de base privada, bajo la forma jurídica de sociedades mercantiles ${ }^{1}$, en unos casos, o como instituciones sujetas a un régimen

1 Gamero Casado, E. y Fernández Ramos, S.: Manual Básico de Derecho Adminis-

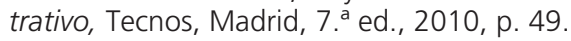


jurídico, organizativo y de funcionamiento propio y particular como el de las Entidades colaboradoras, en otras.

\section{La externalización de la actuación de las Administraciones Públicas}

\subsection{Significado y alcance}

En la actualidad, la simplificación o desburocratización de la organización y del funcionamiento de las Administraciones Públicas se reconoce como uno de los retos más importantes y el objetivo más inmediato del Derecho administrativo, esencial para la construcción de un nuevo modelo de Administración Pública que garantice el servicio objetivo a los intereses generales y la realización efectiva —en cuanto eficaz y eficiente- de los servicios públicos, acorde con los principios constitucionales de la organización y la actuación administrativas proclamados en el artículo 103 de nuestra Norma Fundamental².

En este sentido, merecen significarse las reflexiones del profesor Sebastián Martín-Retortillo calificando la simplificación administrativa como una necesidad inmediata de nuestras Administraciones Públicas que «[...] se enuncia siempre con un significado dinámico y operativo; en definitiva, como tarea a realizar que, según se verá, se proyecta en ámbitos muy distintos. En todo caso, y como punto de partida, parece obligado reconocer la necesidad de llevarla a cabo. Es algo que no cabe cuestionar; tampoco que haya que hacerlo en términos rigurosos y que no admiten demora $[\ldots])^{3}$.

Así pues, el fenómeno de la externalización de la actuación administrativa se configura en el Derecho administrativo actual como una tendencia imparable de transformación de las Administraciones Públicas que, impulsada por las corrientes doctrinales de la denominada Nueva Gestión Pública, facilita y favorece la incorporación de los conocimientos técnicos, así como de las destrezas y habilidades materiales, imprescindibles para garantizar una gestión y una prestación eficaz y eficiente de los servicios públicos.

2 Alomar Olmeda, A.: «Simplificación administrativa», en La Ordenación de las actividades de servicios: Comentarios a la Ley 17/2009, de 23 de noviembre, dir. QuadraSalcedo Fernández del Castillo, T., Aranzadi, Pamplona, 2010, pp. 338 a 345.

3 Martín-Retortillo Baquer, S.: «De la simplificación de la Administración Pública», Revista de Administración Pública, núm. 147, sept.-dic., Madrid, 1998, p. 7. 
En definitiva, la gestión de los servicios públicos mediante personas jurídicas privadas se ha convertido en un elemento clave de la transformación de la organización y el funcionamiento de las Administraciones Públicas de nuestros días, dirigido a materializar y consagrar la realización del Principio constitucional de eficacia de la actuación administrativa4.

\subsection{La prestación de servicios de interés general mediante personas jurídicas de base privada}

A lo largo de la historia y en el camino de su evolución hacia la desregulación o simplificación, se ha generalizado el fenómeno de la externalización de la gestión y prestación de los servicios de interés general mediante el recurso a fórmulas societarias o personas jurídicas de base privada.

La externalización de la actuación de las Administraciones Públicas ha provocado la pérdida del carácter orgánico del concepto de servicio público que pasa a configurarse y definirse a partir su elemento sustantivo o material, relativo a los aspectos o a las técnicas jurídicas propias del Derecho Privado y que son gestionadas tanto por los Poderes Públicos como por los particulares 5 .

Resulta cada vez más frecuente y habitual que los sujetos privados, cuya única relación con las Administraciones Públicas hasta ahora consistía en ser receptores de su actuación en cuanto destinatarios de los servicios públicos, empiecen a desarrollar funciones esencialmente administrativas, ejerciendo funciones y Potestades públicas similares a las que ostentan las Administraciones Públicas ${ }^{6}$.

Sin embargo, y de acuerdo con el profesor SANTAMARÍA PASTOR, el problema se ha planteado, al igual que ha sucedido en el ámbito de la Ad-

4 Sosa Wagner, F.: La gestión de los servicios públicos locales, Civitas, Madrid, 5. ${ }^{\text {e ed. } 2002, \text { p. } 62 .}$

5 Sosa Wagner, F.: La gestión de los servicios públicos locales, Civitas, Madrid, 5. ${ }^{a}$ ed. 2002, p. 74.

6 En este sentido, señala SANTAMARÍA PASTOR que el «el hecho de que personas y organizaciones privadas realicen funciones públicas y ostenten, a tal fin, poderes también inequívocamente públicos, no es una anomalía. En todos los tiempos y países, los Estados han asumido un conjunto de responsabilidades muy superior a las que podían desempeñar con su propio personal y han tenido que confiar parte de ellas a personas y organizaciones privadas, bien que sometidas en este aspecto a un régimen público y al control, más o menos intenso, de las Administraciones titulares de dichas funciones y poderes», Santamaría Pastor, J.A.: Principios de Derecho Administrativo General I, lustel, Madrid, 2. ${ }^{\text {a }}$ ed., 2009, p. 37. 
ministración Instrumental, cuando la encomienda del ejercicio de funciones públicas o de prestación de servicios públicos a través de personas jurídicas de base privada se ha ido improvisando y construyendo de forma empírica, sin la previa existencia de una tipificación legal común de todos los supuestos en que tiene lugar, de tal forma y manera que sus concretas características y régimen jurídico es en cada caso diferente?

Merece significarse a este respecto la sistematización, elaborada por el profesor SANTAMARÍA PASTOR, de los tres modelos básicos en virtud de los cuales se ha venido concretado la encomienda de gestión de los intereses y servicios públicos a los particulares.

Concretamente en los siguientes términos:

a) En primer lugar, un conjunto de entidades asociativas que agrupan a sujetos privados pertenecientes a un colectivo profesional o empresarial. Estas entidades no se constituyen en virtud de pactos privados (como una asociación civil), sino por un acto del poder público, generalmente amparado en una ley previa, de manera que no poseen una forma de personificación asimilable a las existentes en el derecho privado, sino pública y singular: nos referimos a las que genéricamente son conocidas como Corporaciones de Derecho Público (categoría que engloba un conjunto muy variado de entidades: Colegios Profesionales, Cámaras de Comercio, Industria y Navegación, Cámaras Agrarias; Cofradías de Pescadores, Comunidades de Usuarios de recursos hidráulicos y Federaciones Deportivas, entre otras).

b) En segundo lugar, las empresas privadas (normalmente Sociedades Mercantiles) que prestan un servicio público administrativo en virtud de un contrato con la Administración titular del mismo; contrato cuyas cláusulas definen sus respectivos derechos y obligaciones. Por lo general, estas entidades reciben el nombre de concesionarios.

c) Y, por fin, un amplio y heteróclito conjunto de empresas privadas que, por encomienda expresa de la Ley o en virtud de otros títulos habilitantes (autorizaciones), realizan funciones administrativas no calificables como servicios públicos (p.ej. actividades de inspección como sucede en el ámbito de la seguridad industrial) o prestan servicios de interés general y de carácter fundamental para el correcto funcionamiento de un sector $[\ldots]^{8}$.

El fundamento del recurso a estas formas indirectas de prestación de servicios públicos no es otro sino la remisión genérica a las nor-

7 Santamaría Pastor, J.A.: op. cit., p. 35.

8 Santamaría Pastor, J.A.: Principios de Derecho Administrativo General I, lustel, Madrid, 2. ${ }^{a}$ ed., 2009, pp. 37 a 39. 
mas de derecho privado, civil o mercantil, para la determinación del régimen jurídico de actuación y de funcionamiento de estas sociedades en cuanto se refiere a su constitución, organización y funcionamiento, de tal forma y manera que la aplicación de normas propias y específicas de derecho administrativo se reduce o limita exclusivamente a los supuestos en que éstas sociedades actúan en ejercicio de potestades o prerrogativas públicas, ejerciendo a tal efecto funciones públicas ${ }^{9}$.

Las cooperativas de consumo eléctricas forman parte de esta categoría de personas jurídicas de base privada, en cuanto tienen por objeto social la prestación de servicios de interés general esenciales y determinantes del correcto funcionamiento del sector eléctrico ${ }^{10}$.

En este sentido, se configuran como auténticos operadores del sistema a los que les corresponde la realización de cuantas actividades sean necesarias para garantizar tanto la producción como la continuidad en el suministro eléctrico, así como la coordinación de los sistemas de transporte, distribución y comercialización de la electricidad.

\section{Régimen jurídico de la comercialización de la electricidad}

\subsection{Evolución de la regulación del sector eléctrico: del servicio público al servicio de interés general}

La regulación del sector eléctrico, como de tantos otros sectores de actuación de las administraciones públicas ha sido el resultado de la experiencia, de tal forma y manera que se puede afirmar que en el origen y la evolución de la normativa vigente concurren un conjunto de factores sociales, tecnológicos, económicos, empresariales y ambientales específicos.

El sector eléctrico se caracteriza por ser un sector estratégico y de interés general por su objeto, la energía eléctrica, cuya distribución y

9 Santamaría Pastor, J.A.: op. cit., p. 39; Cosculluela Montaner, L.: Manual de Dere-

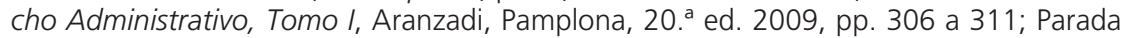
Vázquez, R.: Derecho Administrativo I (parte general), Marcial Pons, Madrid, 18. ${ }^{a}$ ed. 2010; García de Enterría, E.; Fernández Rodríguez, T.R.: Curso de Derecho Administra-

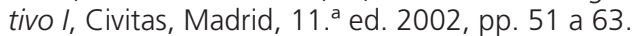

10 Las sociedades cooperativas son formas societarias admitidas en nuestro ordenamiento jurídico para gestión de los servicios públicos. Véase en este sentido, el análisis del profesor Sosa Wagner, F. en La gestión de los servicios públicos locales, ThomsonCivitas, Pamplona, 7. ${ }^{a}$ ed. 2008, pp. 329 a 335. 
suministro se debe garantizar a todos los ciudadanos, intensificando para ello su regulación hasta modelos monopolísticos centralizados, en tanto que se trata de un bien jurídico indispensable para el desarrollo de la vida cotidiana y determinante del crecimiento económico ${ }^{11}$.

La evolución de la normativa del sector eléctrico forma parte de un proceso de transformación de la regulación de los grandes servicios colectivos, como las telecomunicaciones, el gas y los transportes, entre otros, caracterizado por la sustitución del tradicional concepto de servicio público, concebido como servicio de titularidad y gestión públicas y sujeto a normas de derecho administrativo, por un modelo liberalizado en el que se introducen el mercado y la libre competencia en la prestación de los referidos servicios colectivos ${ }^{12}$.

La introducción de este nuevo modelo participativo y de concurrencia competitiva en el sector eléctrico ha sido especialmente compleja por la concurrencia de condicionantes de técnicos y económicos que determinantes de la tendencia al mantenimiento del monopolio del sector en todas sus fases desde la generación o producción de electricidad hasta su distribución y comercialización.

La regulación competitiva del sector eléctrico en nuestro país se ha producido a partir de la aprobación y entrada en vigor de la Ley 54/1997, de 27 de noviembre, del Sector Eléctrico (en adelante LSE)13, en el marco de la desregulación como reto del Derecho administrativo en su proceso de transformación y adaptación a las nuevas realidades tecnológicas, ambientales, económicas y sociales.

Este cambio en la regulación del sector eléctrico coincide con la redefinición del concepto de servicio público para abrirse progresivamente a la competencia y al mercado.

Se pasa, de este modo, desde la reserva a favor del Estado de la titularidad, gestión y regulación de los servicios públicos a la definición y el establecimiento de un conjunto de actividades y obligaciones que se imponen a los particulares que ostenten la condición de prestadores de un servicio de interés general, que tienen por objeto garantizar la universalidad y la efectividad de su prestación ${ }^{14}$.

11 González-Varas Ibáñez, S.: Los mercados de interés general: telecomunicaciones y postales, energéticos y de transportes (Privatización, liberalización, regulación pública y derecho de la competencia), Comares, Granada, 2001, p. 299; Hernández, J.C.: op. cit., pp. 23 a 26.

12 Hernández, J.C.: Regulación y competencia en el sector eléctrico. Evolución, regulación actual y perspectivas de futuro, Thomson-Aranzadi, Pamplona, 2005, p. 19.

13 BOE núm. 285, de 28 de noviembre de 1997.

14 Bacigalupo Saggese, M.: «Electricidad, servicio público y mercado», en Tratado de regulación del sector eléctrico. Tomo I. Aspectos jurídicos, Dir. Becker, F.; Cazorla, 
La liberalización del sector eléctrico se presenta, por tanto, como un proceso decisivo que tiene su origen en la incorporación de España a la Comunidad Económica Europea y que se produce manteniendo su definición y caracterización como servicio de interés general prestado en régimen de libre competencia.

De este modo, la Exposición de Motivos de la vigente LSE afirma que la nueva regulación tiene por objeto «el triple y tradicional objetivo de garantizar el suministro eléctrico, garantizar la calidad de dicho suministro y garantizar que se realice al menor coste posible, todo ello sin olvidar la protección del medio ambiente».

En definitiva, lo que la LSE pretende garantizar es el suministro de energía eléctrica al menor coste económico y ambiental posible, procurando la gestión eficiente de los recursos disponibles en el contexto del mercado y la libre competencia, sin necesidad de acudir a técnicas centralizadas de planificación, explotación y gestión del servicio ${ }^{15}$.

Se debe apuntar a este respecto la reciente presentación por el Gobierno de un Proyecto de Ley de Modificación de la vigente LSE que tiene como finalidad la adecuación de la normativa vigente a las directrices de la Unión Europea para la trasposición de la Directiva sobre normas comunes del mercado interior de la electricidad, destacando como propósitos básicos y fundamentales del nuevo proyecto de ley la liberalización de los mercados y la protección y defensa de los consumidores y usuarios de energía eléctrica ${ }^{16}$.

\subsection{La distinción de actividades en la LSE. La comercialización de la electricidad}

La LSE define su objeto como el de la realización de todas las actividades destinadas al suministro de energía, cuales son: generación, transporte, distribución, comercialización, gestión económica y técnica

\footnotetext{
L.M.; Martínez-Simancas, J. y Sala, J.M., Thomson-Aranzadi, Pamplona, 2009, p. 87.

15 Cruz Ferrer, J.: La liberalización de los servicios públicos y el sector eléctrico. Modelos y análisis de la Ley 54/1997, Marcial Pons, Madrid, 1999, p. 346; Hernández, J.C.: op. cit., p. 84; Nebreda Pérez, J.M.: Distribución eléctrica. Concurrencia de disciplinas jurídicas, Thomson-Aranzadi, Madrid, 2. ${ }^{a}$ ed. 2003, p. 119.

16 La introducción de nuevos criterios de protección de los consumidores más vulnerables y su asimilación al bono social, junto con otras disposiciones relativas a la defensa de los consumidores y usuarios y el fortalecimiento de la independencia de los reguladores de la energía, son las principales novedades del nuevo proyecto de ley de modificación de la LSE, publicado en el BOE núm. 141-1, de 15 de julio de 2011.
} 
e intercambios intracomunitarios e internacionales. Mediante la regulación de dichas actividades el legislador pretende adecuar el suministro eléctrico a las necesidades de los consumidores, en base a criterios de eficiencia, racionalización y optimización de los recursos disponibles.

Para ello, la LSE establece dos ámbitos objetivos y diferenciados en su regulación distinguiendo las actividades del sector eléctrico que son propiamente competitivas como la producción, la generación y la comercialización de la electricidad, de las actividades reguladas como el transporte y la distribución.

Nos centraremos en el análisis del régimen jurídico de una de las actividades competitivas, la comercialización de la electricidad.

\section{a) DeFINICIÓN DE LA ACTIVIDAD DE COMERCIALIZACIÓN DE ELECTRICIDAD}

La actividad de comercialización de la energía eléctrica, al igual que la producción, es una actividad expresamente calificada por la LSE como actividad competitiva o liberalizada que se encuentra sometida, no obstante, a determinadas medidas reguladoras que tienen por objeto garantizar el suministro efectivo de electricidad y organizar el funcionamiento efectivo del mercado eléctrico.

Se puede definir, por tanto, como la actividad por la que una persona jurídica vende energía eléctrica a un usuario no acogido a tarifa y a precio libre. A tal efecto, el artículo 44.1 de la LSE define a los agentes comercializadores de energía eléctrica como a las personas jurídicas que suministran electricidad a aquellos usuarios en los que concurre la condición de cualificados por haber decidido no acogerse a tarifa ${ }^{17}$.

La comercialización de electricidad se configura en la LSE como una actividad que se presta o realiza en régimen de libre competencia basada en los principios de libertad de entrada y acceso a las redes y libertad de contratación y formación competitiva de los precios ${ }^{18}$.

La libre entrada o el libre acceso al mercado de la comercialización de la electricidad está supeditada al cumplimiento por el sujeto comercializador de los tres requisitos siguientes: autorización administrativa o comunicación previa de inicio de actividad y declaración responsable,

17 En relación con esta cuestión, HeRnÁNDEZ, J. señala que la segmentación del mercado regulado en la LSE no se produce en términos de consumidores cualificados y no cualificados, sino como consumidores y usuarios de electricidad que decidan, o no, acogerse a tarifa. Véanse sus reflexiones en Hernández, J.C.: op. cit., p. 98.

18 Hernández, J.C.: op. cit., pp. 99; Nebreda Pérez, J.M.: op. cit., p. 156. 
inscripción en el registro administrativo de distribuidores, comercializadores y consumidores y prestar caución o garantía para atender a las demandas de energía.

\section{b) REQUisitos DE LOS AGENTES COMERCIALIZADORES}

De acuerdo con lo dispuesto en el artículo 9.1.h) LSE, las entidades comercializadoras de energía eléctrica tienen que ser personas jurídicas que, accediendo a las redes de transporte y distribución, tienen como función la venta de energía eléctrica a los consumidores cualificados o a otros sujetos del sistema.

Para ello, el agente comercializador debe acreditar ante la Administración Pública competente su capacidad técnica, legal y económica para la realización de la referida actividad de venta de electricidad.

En este sentido, deben significarse las modificaciones introducidas para la acreditación de tales circunstancias a partir de la entrada en vigor de la Ley 17/2009, de 23 de noviembre, sobre el libre acceso a las actividades de servicios y su ejercicio, por la que se incorpora al derecho español la Directiva 2006/123/CE del Parlamento Europeo y del Consejo, de 12 de diciembre de 2006, relativa a los servicios en el mercado interior, en adelante Directiva de servicios.

Esta Ley 17/2009 se incorpora a nuestro ordenamiento jurídico con el propósito de consolidar los principios reguladores compatibles con las libertades básicas de establecimiento y de libre prestación de servicios y suprimir las barreras o trabas que restringen el acceso a las actividades de servicios y su ejercicio.

En particular, la Ley 17/2009 pone el acento en que los instrumentos de intervención de las Administraciones Públicas en este sector deben ser conformes con los principios de no discriminación, de justificación por razones imperiosas de interés general y de proporcionalidad para atender esas razones.

Por otro lado, dicha norma exige que se simplifiquen los procedimientos, evitando dilaciones innecesarias y reduciendo las cargas administrativas a los prestadores de servicios. Adicionalmente, se refuerzan las garantías de los consumidores y usuarios de los servicios, al obligar a los prestadores de servicios a actuar con transparencia tanto respecto a la información que deben proveer en materia de reclamaciones.

Con el fin de alcanzar el objetivo de reformar el marco regulador del acceso a las actividades de servicios ha sido necesario un ejercicio de evaluación y adaptación de toda la normativa vigente para adecuarla a los fines y objetivos que establece la Ley 17/2009. 
En este contexto se ha aprobado la Ley 25/2009, de 22 de diciembre, de modificación de diversas leyes para su adaptación a la Ley sobre el libre acceso a las actividades de servicios y su ejercicio para adaptar la normativa estatal de rango legal a lo dispuesto en la precitada Ley $17 / 2009$.

En cuanto se refiere al sector eléctrico, la adaptación de la normativa a los nuevos requerimientos se ha producido a partir de la aprobación del Real Decreto 198/2010, de 26 de febrero, que tiene por objeto el desarrollo de los preceptos de la vigente LSE modificados por la Ley 25/2009, de 22 de diciembre ${ }^{19}$.

Respecto de la regulación de la actividad de comercialización de la electricidad, el artículo 3 del precitado Real Decreto 198/2010, introduce importantes modificaciones, entre las que destacamos especialmente las dos siguientes:

1. ${ }^{\text {a }}$ Respecto de las obligaciones de las empresas comercializadoras se sustituye la autorización administrativa previa por una comunicación de inicio de actividad que deberán presentar ante la Dirección General de Política Energética y Minas del Ministerio de Industria, de acuerdo con el modelo establecido en el anexo 6.1 del Real Decreto 198/2010 y en la que se debe especificar el ámbito territorial en el que se vaya a desarrollar la actividad.

El interesado debe acompañar a la comunicación de inicio de actividad una declaración responsable sobre el cumplimiento de los requisitos que exige la legislación vigente para la comercialización de la electricidad.

Se impone asimismo al interesado la obligación de comunicar cualquier circunstancia modificativa de los datos incluidos tanto en la comunicación de inicio de actividad como en la declaración responsable originaria.

2. ${ }^{a}$ Por otra parte, el Real Decreto 198/2010 modifica los requisitos necesarios para realizar la actividad de comercialización, acreditativos de la capacidad legal, técnica y económica de las empresas comercializadoras.

La acreditación de la capacidad legal de las empresas que realizan la actividad de comercialización de electricidad se formaliza mediante su configuración como sociedades mercantiles debidamente inscritas en el registro correspondiente.

19 BOE núm. 63, de 13 de marzo de 2010. 
Respecto de su capacidad técnica, dichas sociedades deben acreditar el cumplimiento de los requisitos exigidos por la LSE a los sujetos compradores en el mercado de producción de energía eléctrica conforme a los procedimientos de operación técnica y, en su caso, las reglas de funcionamiento y liquidación del mercado de producción.

Finalmente, la capacidad económica de las empresas interesadas en la comercialización de la electricidad se debe acreditar mediante la prestación de las cauciones o avales exigibles para la adquisición de energía en el mercado de producción de electricidad ante los operadores del sistema y del mercado.

\section{Las cooperativas eléctricas}

\subsection{Breve aproximación al origen y evolución de las cooperativas eléctricas}

Durante la primera mitad del siglo xx surgen las primeras cooperativas eléctricas en nuestro país, con el objetivo de resolver el problema de la falta de suministro eléctrico en pequeños núcleos de población y para poner en marcha e impulsar el desarrollo de iniciativas industriales en un momento caracterizado por la ausencia de infraestructuras a través de las que garantizar el servicio eléctrico para toda la población 20 .

Tras la Guerra Civil se experimenta un proceso de paulatina desaparición de estas sociedades cooperativas como consecuencia de las fuertes restricciones económicas derivadas de la postguerra y de la creciente presión ejercida por las grandes mercantiles interesadas por mantener y reforzar su presencia en un sector cada vez más monopolizado.

Sin embargo, las cooperativas eléctricas subsisten a lo largo del tiempo, existiendo en la actualidad varias sociedades que actúan como distribuidoras y como comercializadoras de energía eléctrica, que adquieren al por mayor en el mercado, repercutiendo el ahorro generado a sus socios en el momento de la comercialización ${ }^{21}$.

20 Las cooperativas eléctricas tienen, por lo tanto, su origen en lugares apartados y barrios periféricos de las ciudades en los que no les interesaba invertir a las grandes mercantiles por la difícil amortización o rentabilización de las nuevas redes de distribución necesarias para garantizar el suministro de energía eléctrica en estos lugares.

21 En la actualidad existen en nuestro país numerosas cooperativas eléctricas, distribuidoras y comercializadoras, la mayoría emplazadas en la Comunidad Valenciana. Entre otras, Cooperativa Eléctrica de Castelar, Cooperativa Eléctrica Albaterense, Coo- 
Las cooperativas de consumo eléctricas centran su actividad en el mantenimiento de las redes de distribución de energía con la finalidad de mejorar la calidad del suministro y evitar así las pérdidas en la actividad de transporte y comercialización.

De este modo, las cooperativas pueden repercutir el ahorro generado a sus socios, ofreciendo precios muy competitivos y baratos en el mercado, alcanzando incluso niveles tarifarios similares al costo del bono social.

Al disponer de escasos recursos económicos que les permitan invertir en nuevas redes, las cooperativas eléctricas centran su actividad en áreas geográficas reducidas como pueblos, núcleos rurales y pequeños barrios en los que les resulta más fácil su desarrollo por la concentración de socios en la misma zona o área geográfica.

En general, se puede afirmar que, en la actualidad, las cooperativas eléctricas representan un modelo de buena gestión que les permite suministrar energía eléctrica a un precio entre un 5\% y un 7\% más barato a sus socios y a un número creciente de clientes no socios. En este sentido, la Alianza Cooperativa Internacional ha reconocido el importante papel que desempeñan las sociedades cooperativas en relación con el ahorro y la eficiencia energética.

Debe significarse a este respecto, la contribución de las sociedades cooperativas al modelo de consumo y generación de energía eléctrica propugnado en la vigente Ley 2/2011, de 4 de marzo, de Economía Sostenible ${ }^{22}$, en adelante LES, compatible con la normativa y los objetivos comunitarios y con los esfuerzos internacionales en la lucha contra el cambio climático ${ }^{23}$.

perativa Eléctrica Benéfica Catralense, Cooperativa Popular de Fluido Eléctrico de Camprodon, Cooperativa Valenciana Electrodistribuidora de Fuerza y Alumbrado Serrallo, Electrica Algimia de Alfara, Sociedad Cooperativa Valenciana, Electrica Vinalesa, S.C.V., Eléctrica de Chera, S.C.V., Eléctrica de Guadassuar, S.C.V., Eléctrica de Meliana, S.C.V., Eléctrica de Sot de Chera, S.C.V., Eléctrica del Pozo, Sociedad Cooperativa Madrileña, Eléctrica Nuestra Señora de Gracia, S.C.V., Eléctrica Popular, S. Cooperativa Madrileña, Electrodistribuidora de Fuerza y Alumbrado, S.C.V., Electroharinera Belsetana, Sociedad Cooperativa, Fluido Eléctrico de Museros, S.C.V., Grupo de electrificación rural de Binefar y comarca, S. Coop. R.L., Benéfica de consumidores de electricidad "San Francisco de Asís» de Crevillent, Suministros especiales Alginetenses, S.C.V. Véase en http://www. coop-electricas.com y http://coopelectricas.ecsocial.com.

22 BOE núm. 55, de 5 de marzo de 2011.

23 El Capítulo I del Título III define el régimen jurídico de lo que denomina un modelo energético sostenible enunciando como Principios de la política energética los de Garantía de la seguridad del suministro; Eficiencia económica y Sostenibilidad ambiental. 
A tales efectos, la LES (artículo 77.3) impone al Gobierno la obligación de impulsar la diversificación de las fuentes de suministro energético, el desarrollo eficiente de las infraestructuras y redes de transmisión, la transparencia y la competitividad de los mercados, la suficiencia de las retribuciones y la creciente incorporación de las energías renovables y las políticas de ahorro y eficiencia.

En este nuevo contexto, destaca el papel de las cooperativas de consumo distribuidoras y comercializadoras de electricidad, en tanto que desarrollan un importante trabajo por su contribución a la lucha contra el cambio climático, siendo destacables sus esfuerzos en la utilización de energías renovables, reconocidos expresamente por la Alianza Cooperativa Internacional ${ }^{24}$.

\subsection{Aproximación al marco jurídico básico de las Cooperativas eléctricas}

De acuerdo con la declaración formulada en el año 1995 por la Alianza Cooperativa Internacional, el fenómeno cooperativista está basado en los valores de la autoayuda, autorresponsabilidad, democracia, igualdad, equidad y solidaridad.

En la actualidad, se acepta mayoritariamente la definición del artículo 1 LCPV según la cual la cooperativa es una empresa que tiene por objeto prioritario la promoción de actividades económicas y sociales de sus miembros y la satisfacción de sus necesidades con la participación activa de los mismos, observando los principios cooperativos y atendiendo a la comunidad de su entorno ${ }^{25}$.

En definitiva, lo que distingue o singulariza a la entidad cooperativa de otras personas jurídicas con carácter empresarial no es el tipo o clase de actividad a desarrollar, sino los principios inspiradores y rectores de su estructura y funcionamiento: los principios cooperativos revisados periódicamente por la $\mathrm{ACl}$ que diferencian a las cooperativas de cualquier otro tipo de empresas y que se concretan en los siguientes: la adhesión voluntaria y abierta de sus miembros, la gestión democrática por los socios, participación económica de los socios, autonomía e independencia, educación, formación e información, cooperación entre cooperativas e interés por la comunidad ${ }^{26}$.

24 http://www.empresaytrabajo.coop

25 Gadea Soler, E.: «Estudio sobre el concepto de cooperativa: referencia a los principios cooperativos y a su discutida vigencia», JADO. Boletín de la Academia Vasca de Derecho, año VII, núm. 17, Bilbao, 2009, p. 170.

26 Gadea Soler, E.: op. cit., pp. 177 a 183. 
Tanto la Ley 27/1999, de 16 de julio de Cooperativas ${ }^{27}$ como la Ley 4/1993, de 24 de julio, de Cooperativas de Euskadi28, definen las Sociedades Cooperativas como sociedades integradas por personas que se asocian de forma voluntaria con el fin de desarrollar en común una o varias actividades de carácter empresarial, acogiéndose a un modelo organizativo al servicio de sus miembros, cuyo principal objetivo es la promoción de las actividades económicas y sociales de aquellos, para el desarrollo de una empresa de propiedad conjunta y gestión democrática, con plena observancia y respeto de los principios cooperativos en su estructuración y funcionamiento.

Sea cual fuere la actividad cooperativizada debe servir a una función social, entendida como satisfacción de alguna de las necesidades de promoción de un interés de carácter socioeconómico de sus miembros que se anteponga al interés de un concreto y determinado beneficio económico.

La Ley Vasca regula las diferentes clases de cooperativas en el capítulo I de su Título II, especificando que éstas además de someterse a los principios configuradores establecidos en la ley, están sujetas a la legislación específica que resulte en cada caso aplicable, en función de cuál sea la concreta actividad que a la que se dediquen.

En el supuesto que nos ocupa, de la comercialización de la electricidad a través de sociedades cooperativas, la forma jurídica adecuada sería la de las cooperativas de consumo, en tanto que, de acuerdo con lo dispuesto en el artículo 105 de la Ley Vasca de Cooperativas tienen por objeto «procurar bienes o prestar servicios para el uso o consumo de sus socios y de quienes con ello convivan, así como la defensa y promoción de los derechos e intereses legítimos de los consumidores y usuarios. Pueden ser socios de estas cooperativas las personas físicas y las entidades u organizaciones que tengan el carácter de destinatarios finales»

De este modo, las cooperativas eléctricas se constituyen como cooperativas de consumo que tienen por objeto la distribución de la energía eléctrica y la comercialización de todo tipo de productos energéticos relacionados con ella, en los términos previstos en la legislación vigente, así como la prestación de todos los servicios y actividades relacionados directa o indirectamente con dichas operaciones.

27 BOE núm. 170, de 17 de julio de 1999.

28 BOPV núm. 135, de 19 de julio de 1993. 


\subsection{Reconocimiento normativo y jurisprudencial de las cooperativas eléctricas como sociedades comercializadoras de electricidad}

Tal y como se ha señalado antecedentemente, la LSE (artículo 9.1.h) reconoce como entidades comercializadoras de energía eléctrica a todas las personas jurídicas que se dediquen a su venta y distribución.

Sin embargo, el Real Decreto 1955/2000, de 1 de diciembre ${ }^{29}$, por el que se regulan las actividades de transporte, distribución, comercialización y los procedimientos de autorización de instalaciones de energía eléctrica, en su artículo 73.1.a) excluye formalmente a las sociedades cooperativas de la actividad de comercialización de energía eléctrica, en tanto que exigen como requisito previo y necesario para el desarrollo de dicha actividad, la presentación de la escritura pública de constitución de la empresa «debidamente inscrita en el Registro Mercantil».

Esta regulación, contenida en el precitado Real Decreto 1955/2000, de 1 de diciembre, ignora la existencia de sociedades cooperativas centenarias dedicadas a proporcionar suministro eléctrico a sus socios $y$, en ocasiones, a otros ciudadanos que, como tales cooperativas de consumo, figuran inscritas únicamente en el Registro de Cooperativas, puesto que por su propia naturaleza societaria no pueden acceder a su inscripción en el Registro Mercantil.

Debe significarse a este respecto que, tanto la legislación estatal como autonómica vigente en materia de cooperativas reconocen y afirman la personalidad jurídica de estas sociedades a partir de su inscripción en el Registro de Cooperativas, que tiene por objeto su calificación y clasificación conforme a los principios de publicidad, legitimación, privacidad y tracto sucesivo, gozando las inscripciones practicadas en sus libros de sendas presunciones de veracidad y exactitud.

Más aún, tanto la Ley 27/1999, de 16 de julio de Cooperativas como la Ley 4/1993, de 24 de julio, de Cooperativas de Euskadi, en sus respectivos artículos primeros, afirman que cualquier actividad económica lícita podrá ser organizada y desarrollada mediante una sociedad constituida al amparo de estas normas. Declaración que, para el supuesto específico de las cooperativas de consumidores y usuarios se reconoce expresamente en el Texto Refundido de la Ley General para la Defensa de los Consumidores y Usuarios aprobada por Real Decreto Legislativo núm. 1/2007, de 16 de noviembre ${ }^{30}$.

30 BOE núm. 287, de 30 de noviembre de 2007. 
Del mismo modo, el Tribunal Supremo de Justicia ha reconocido expresamente a las sociedades cooperativas como personas jurídicas legalmente habilitadas para el desarrollo de la actividad de comercialización de energía eléctrica, mediante Sentencia dictada con fecha 16 de octubre de $2003^{31}$, con ocasión de la impugnación de diversos preceptos del Real Decreto 1955/2000, en la que el Alto Tribunal declara ilegal la exigencia de que únicamente puedan ejercer la actividad de comercialización de la electricidad las sociedades inscritas en el Registro Mercantil32.

31 STS de 16 de octubre de 2003, RJ [2003/9558].

32 Véase a tal efecto el Fundamento Jurídico Tercero de la STS de 16 de octubre de 2003, en cuanto afirma expresamente que «[...] la impugnación del tercero de los preceptos recurridos [el artículo 73.1, letra a) del Real Decreto 1955/2000] se fundamenta en que su aplicación privaría a las sociedades cooperativas de la posibilidad de comercializar energía eléctrica.

Según los demandantes, el requisito previo exigido a efectos de autorización por este epígrafe del artículo 73 (la preceptiva aportación de la escritura de constitución de la empresa debidamente inscrita en el Registro Mercantil) supone tanto como impedir que las sociedades cooperativas, sin acceso a dicho Registro, puedan realizar la actividad de comercialización de energía eléctrica.

Esta conclusión (que la norma reglamentaria impide a las cooperativas comercializar energía eléctrica) es aceptada por todas las partes del litigio y las razones de la restricción son defendidas por el Abogado del Estado y por alguna de las codemandadas sobre la base de la aplicación de diversos preceptos de la Ley 27/1999, de 16 de julio, General de Cooperativas.

La demanda debe prosperar en este extremo. Las entidades comercializadoras de energía eléctrica son, a tenor de la Ley 54/1997 (artículo 9.1.h), aquellas personas jurídicas que, accediendo a las redes de transporte o distribución, tienen como función la venta de energía eléctrica a los consumidores cualificados o a otros sujetos del sistema. La Ley no ha limitado la tipología de personas jurídicas que pueden ser comercializadoras, a diferencia de los que, por una vía indirecta, hace el reglamento ahora impugnado. Dado que la comercialización se puede ejercer libremente (artículo 11 de la Ley 54/1997) en los términos de la referida Ley, una restricción de esta naturaleza debería haber sido prevista en ella y no en normas de rango subordinado.

La aplicación combinada de los diferentes preceptos de la Ley 27/1999, de 16 de junio, de Cooperativas no lleva a la conclusión propugnada por el Reglamento, sino a la contraria. Su artículo 1 apartado segundo, permite a este tipo de sociedades desarrollar cualquier actividad económica lícita, entre las que se encuentra, sin duda, la de de comercializar energía eléctrica en cuanto actividad ya liberalizada. El artículo 4, apartado primero, de la misma Ley 27/1999 autoriza asimismo a las sociedades cooperativas para realizar actividades y servicios cooperativizados con terceros no socios si así lo prevén sus estatutos, de modo que nada obsta a que las cooperativas satisfagan las demandas de energía eléctrica no sólo de sus socios sino también de terceros, en paridad de condiciones con otras personas jurídicas.

El contenido de la Disposición Adicional Quinta de la Ley 27/1999 no es un obstáculo a cuanto venimos diciendo. A tenor de ella, las entregas de bienes y prestaciones de servicios proporcionadas por las sociedades cooperativas a sus socios no tienen 
Finalmente, el reconocimiento normativo de las sociedades cooperativas como comercializadoras de electricidad se ha consagrado a través del Real Decreto 198/2010, de 26 de febrero, por el que se adaptan determinadas disposiciones relativas al sector eléctrico a lo dispuesto en la Ley 25/2009, de modificación de diversas leyes para su adaptación a la ley sobre el libre acceso a las actividades de servicios y su ejercicio 33 .

En concreto, mediante la modificación del contenido del artículo 73 del Real Decreto 1955/2000, que en su nueva redacción, al enunciar los requisitos necesarios para el ejercicio de la actividad de comercialización de la electricidad, únicamente exigen que las empresas acrediten su capacidad mediante su inscripción en el correspondiente Registro Público, sin que existan más limitaciones o reservas.

\section{A modo de conclusión}

El camino hacia la simplificación y la progresiva desburocratización de la organización y de la actuación de las Administraciones Públicas se configura en la actualidad como uno de los retos más importantes y significativos del derecho administrativo de nuestro tiempo. En este

la consideración de ventas. Tal precepto-que ni siquiera es aplicable a terceros para los que ninguna dificultad hay en mantener la existencia de ventas de energía-no significa que no se produzca una relación jurídica determinada, llámese como se quiera, en cuya virtud la sociedad hace entrega de un bien o servicio a favor de uno o varios socios concretos que, en cuanto a tales sujetos singulares, no se identifican con aquella. Si se tiene en cuenta que el régimen económico de la comercialización viene determinado por las condiciones que pacten las partes (artículo 11.3 de la Ley 54/1997) y que, en el caso de los comercializadores, la transmisión de la propiedad de la energía eléctrica se entenderá producida, salvo pacto en contrario, cuando la misma tenga entrada en las instalaciones del cliente, el mandato contenido en la ya citada Disposición Adicional Quinta de la Ley 27/1999 no impide que las sociedades cooperativas puedan comercializar energía eléctrica.

La conclusión de todo ello es que el precepto (artículo 73 del Real Decreto 1955/2000) debe ser anulado en cuanto excluye a las sociedades cooperativas de la comercialización de electricidad. Lo que ha de traducirse, para garantizar a la vez una mayor seguridad jurídica y la anulación de sólo lo incompatible con el principio de jerarquía normativa, en la supresión del adjetivo «mercantil» que contiene el artículo 73.1 del Real Decreto 1955/2000. Aún cuando no nos corresponde determinar la forma en que ha de quedar redactado el precepto que, eventualmente, sustituya al anulado, no podemos dejar de subrayar que la supresión del citado adjetivo es compatible con una solución como la sugerida por el Consejo de Estado-cuyo preceptivo informe, desatendido en este punto por el Gobierno, propugnaba la ilegalidad de este precepto reglamentario-en el sentido de que bastaría la referencia a la inscripción en el registro público correspondiente».

33 BOE núm. 63, de 13 de marzo de 2010. 
nuevo contexto, cada vez más participativo, los sujetos privados, investidos de diversas personificaciones jurídicas asumen la gestión y prestación de diferentes servicios de interés general.

En el supuesto analizado del sector eléctrico, las cooperativas de consumo destacan por el ejercicio de las actividades de distribución y comercialización de energía eléctrica y otros productos energéticos relacionados a bajo coste, tanto a sus socios como, cada vez en más ocasiones, a terceros usuarios.

Las primeras cooperativas eléctricas surgieron en nuestro país como cooperativas de consumo que, a comienzos del siglo $x x$, se constituyeron en el contexto de pequeños núcleos de población. Tras la Guerra Civil sufrieron un proceso de reducción o limitación como consecuencia de las restricciones derivadas de la postguerra y de la presión creciente de las grandes mercantiles que consolidaban sus posiciones en un sector que caminaba hacía su configuración como uno de los grandes monopolios del Estado.

Desde un punto de vista sustantivo o material, las cooperativas eléctricas se erigen como modelos a seguir por su trabajo relacionado con la búsqueda y experimentación de nuevos modelos de consumo y generación de energía eléctrica y por su compromiso en la lucha contra el cambio climático y con el ahorro energético, así como con la incorporación de energías renovables al proceso de producción de electricidad.

Por otra parte, y desde un punto de vista estrictamente formal, el reconocimiento de las cooperativas eléctricas como agentes comercializadores de energía se ha incorporado a nuestro ordenamiento jurídico a través del Real Decreto 198/2010, de 26 de febrero, por el que se modifica el artículo 73 del Real Decreto 1955/2000, de 1 de diciembre, por el que se regulan las actividades de transporte, distribución, comercialización, suministro de electricidad, junto con los procedimientos de autorización de instalaciones de energía eléctrica.

En definitiva, se puede concluir que las cooperativas de consumo distribuidoras y comercializadoras de electricidad representan, en la actualidad, un modelo de eficiencia y buena gestión en la prestación del servicio de interés general consistente en el suministro de electricidad, que les permite garantizar el abastecimiento de energía tanto a sus socios como a cada vez un mayor número de clientes, a precios más económicos y competitivos y en mérito y base a principios y procedimientos de actuación propios de un modelo energético sostenible, destacando la obra social desarrolla a este respecto por estas sociedades. 